\title{
Eurolntervention
}

\section{Impact of arterial injury on neointimal hyperplasia after implantation of drug-eluting stents in coronary arteries: an intravascular ultrasound study}

Parham Eshtehardi ${ }^{1}$, MD; Stéphane Cook ${ }^{1}$, MD; Simon Wandel ${ }^{2}$, BA; Lorenz Räber ${ }^{1}$, MD; Peter Wenaweser ${ }^{1}$, MD; Mario Togni ${ }^{1}$, MD; Rolf Vogel ${ }^{1}$, MD, PhD; Ali Garachemani ${ }^{1}$, MD; Franz R. Eberli ${ }^{3}$, MD; Thomas F. Lüscher ${ }^{3}$, MD; Peter Jüni' ${ }^{2,4}$, MD; Otto M. Hess ${ }^{1}$, MD; Bernhard Meier ${ }^{1}$, MD; Stephan Windecker ${ }^{1,4 *}$, MD

1. Department of Cardiology, Bern University Hospital, Bern, Switzerland; 2. Institute of Social and Preventive Medicine, University of Bern, Bern, Switzerland; 3. Department of Cardiology, University Hospital, Zurich, Switzerland; 4. Clinical Trial Unit, Bern University Hospital, Bern, Switzerland

\section{KEYWORDS}

Intravascular ultrasound, arterial injury, drug-eluting stent, neointimal hyperplasia

\begin{abstract}
Aims: We investigated the impact of arterial injury on neointimal hyperplasia following implantation of drugeluting stents (DES).

Methods and results: A total of 196 patients with 223 segments (sirolimus-eluting stents [SES]: 104, paclitaxel-eluting stents [PES]: 119) underwent intravascular ultrasound eight months after DES implantation. Arterial injury was defined as the balloon-to-artery ratio (BAR). Segments were categorised into two groups: high BAR defined as BAR>1.1 (120 segments), and low BAR defined as BAR $\leq 1.1$ (103 segments). Baseline clinical characteristics were similar for both groups. Although reference vessel diameter was smaller, stent diameter, maximal balloon pressure and balloon diameter were higher in the high BAR compared with the low BAR group. Lumen ( $7.10 \pm 1.91$ vs. $6.25 \pm 1.69, p=0.001)$, stent $(7.31 \pm 1.95$ vs. $6.41 \pm 1.80, p=0.001)$, and external elastic membrane ( $17.1 \pm 4.9$ vs. $14.8 \pm 4.0, p<0.0001)$ areas $\left(\mathrm{mm}^{2}\right)$ were higher, but neointimal hyperplasia $(0.21 \pm 0.36$ vs. $0.16 \pm 0.48, p=0.42)$ area $\left(\mathrm{mm}^{2}\right)$ was similar in the high BAR compared with the low BAR group. Arterial injury as assessed by BAR was not associated with the amount of neointimal hyperplasia $\left(R^{2}=0.003, p=0.40\right)$.
\end{abstract}

Conclusions: Arterial injury does not correlate with the amount of neointimal hyperplasia following DES implantation. Conventionally aggressive DES implantation techniques do not adversely affect long-term outcome with respect to restenosis.

\footnotetext{
* Corresponding author: Department of Cardiovascular Diseases, Bern University Hospital, 3010 Bern, Switzerland

E-mail: stephan.windecker@insel.ch
} 


\begin{tabular}{|ll|}
\hline \multicolumn{2}{|l|}{ Abbreviations } \\
BAR & balloon-to-artery ratio \\
CSA & cross sectional area \\
EEM & external elastic membrane \\
IVUS & intravascular ultrasound \\
MACE & major adverse cardiac events \\
PES & paclitaxel-eluting stents \\
PCI & percutaneous coronary intervention \\
RVD & reference vessel diameter \\
SES & sirolimus-eluting stents \\
TLR & target lesion revascularisation \\
\hline
\end{tabular}

\section{Introduction}

Coronary artery stent implantation results in arterial overstretch or even deep arterial injury initiating a vasculoproliferative cascade characterised by platelet adhesion, leucocyte diapedesis, smooth muscle proliferation and migration resulting in neointimal hyperplasia. The amount of neointimal proliferation and therefore restenosis has been shown to correlate with the degree of arterial injury following implantation of bare metal stents (BMS) in both experimental models and humans. ${ }^{1-6}$ These pathophysiological considerations may have clinical implications since stent implantation is usually guided by visual rather than quantitative angiographic or intravascular ultrasound (IVUS) and may give rise to a mismatch between stent and arterial dimensions. On one extreme, stent overstretch potentially promotes neointimal hyperplasia for the reasons mentioned above, which may be particularly problematic in patients with small vessels or diabetes owing to their higher propensity for restenosis. ${ }^{7,8}$ Conversely, stent under-expansion has been associated with a higher rate of restenosis, target lesion revascularisation as well as early stent thrombosis, owing to the smaller cross-sectional stent area. ${ }^{9-13}$

Drug-eluting stents (DES) releasing antiproliferative agents directly into the arterial wall effectively reduce neointimal hyperplasia and therefore restenosis compared with bare metal stents. However, stent overstretch or stent under-expansion may result in altered pharmacodynamics of local drug delivery and therefore may impact on the efficacy of DES. ${ }^{14}$ Moreover, the relationship between arterial injury and neointimal hyperplasia following implantation of DES is not well established. We therefore aimed to investigate the impact of arterial injury, approximated as balloon-to-artery ratio (BAR), on the amount of neointimal hyperplasia as assessed by IVUS following implantation of DES in patients with coronary artery disease.

\section{Methods}

\section{Patient population}

Patients of the present study constitute a subpopulation of the SIRTAX trial. ${ }^{15}$ In this prospective, single blind, randomised controlled study, 1,012 patients were randomly assigned to receive either a sirolimus-eluting stent (SES) (Cypher, Cordis, Miami Lakes, FL, USA) (503 patients) or a paclitaxel-eluting stent (PES) (Taxus Express, Boston Scientific Corp., Natick, MA, USA) (509 patients).
Of the overall population 540 patients underwent repeat angiography at eight months. From these, the first 236 patients underwent IVUS at the time of the 8-month angiographic follow-up (Figure 1). They constitute the patient population of the present study.

Eligible patients provided written informed consent. The study complied with the Declaration of Helsinki regarding investigations in humans and was approved by the ethics committees at the University Hospital Bern and University Hospital Zurich, Switzerland. There was no industry involvement in the design, conduct, or analysis of the study.

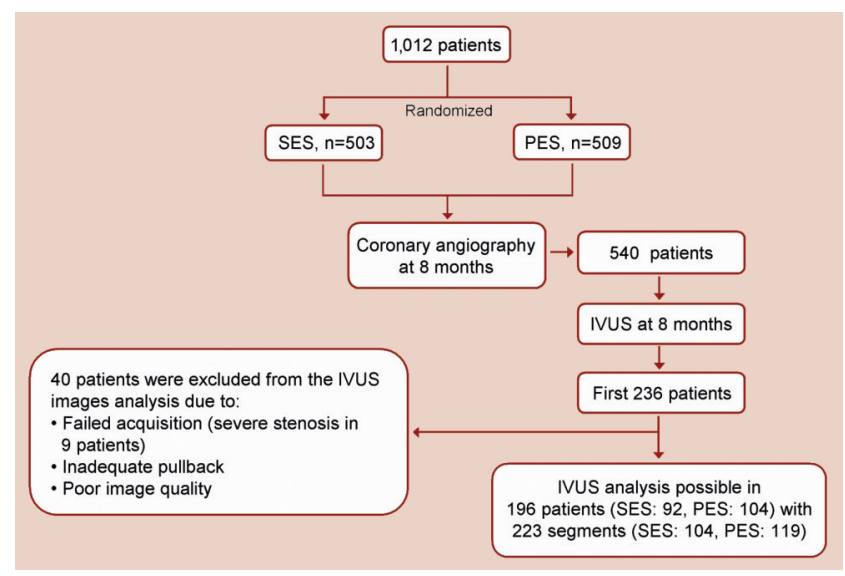

Figure 1. Flow chart of study.

\section{Quantitative coronary angiography}

Coronary angiograms were digitally recorded at baseline, immediately after stent implantation, and at follow-up, and were assessed at the angiographic core laboratory of the Bern University Hospital. Angiogram readers were blinded for the type of stent implanted. Simultaneous biplane projections were acquired and rotation and angulation were adapted to minimise foreshortening of the target vessel. Two orthogonal views were averaged for biplane assessment in projections that showed the stenosis best. Identical views were used for all follow-up examinations. Digital angiograms were analysed with the use of an automated edge-detection system (CAAS II; Pie Medical Imaging, Maastricht, The Netherlands). The intraobserver and interobserver reliabilities of the quantitative measurements have been reported previously. ${ }^{16}$

Quantitative measurements included the reference vessel diameter (RVD), the minimal lumen diameter (MLD), percentage of diameter stenosis (defined as the diameter of the reference vessel minus the minimal luminal diameter, divided by the reference diameter and multiplied by 100), and late luminal loss (the difference between the minimal luminal diameter after the procedure and the minimal luminal diameter at follow-up). Binary restenosis was defined as stenosis $>50 \%$ in the target lesion at angiographic follow-up. All angiographic measurements of the target lesion were obtained in the stented segment (in stent) and within the margins $5 \mathrm{~mm}$ proximal and distal to each stent edge (in segment).

The maximal balloon diameter was determined for each stented segment using the maximal implantation or post-dilatation pressure 
according to the manufacturers' compliance chart. BAR was defined as the ratio of maximal balloon diameter divided by preprocedure RVD.

\section{IVUS image acquisition and analysis}

IVUS imaging was performed after anticoagulation and intracoronary administration of $0.2 \mathrm{mg}$ nitroglycerine using a motorised pullback $(0.5 \mathrm{~mm} / \mathrm{s})$ and Eagle Eye ${ }^{\circledR}$ scanner (Volcano Therapeutics, Inc., Rancho Cordova, CA, USA). Images were continuously recorded throughout the stent and at least $5 \mathrm{~mm}$ distal and proximal to the stent. Images were recorded digitally onto a CD and analysed offline at an independent core laboratory. All analyses were performed blinded to treatment protocols. Quantitative analysis was performed off-line according to criteria of the American College of Cardiology Clinical Consensus document on IVUS. ${ }^{17}$ Using computerised planimetry (In-Vision View ${ }^{\circledR}$ 1.0, Medimatic Inc., Genoa, Italy), the external elastic membrane (EEM), the lumen, and stent cross-sectional areas (CSA) at stented and reference segments were measured every two millimetre within the stent and every millimetre $5 \mathrm{~mm}$ proximal and distal to each stent edge, and were averaged over the length of the analysed segment. Neointima was calculated as stent minus lumen CSA measures, and neointima CSA obstruction percent was calculated as neointima CSA divided by stent CSA. Incomplete stent apposition was defined as lack of contact between at least one strut and the underlying arterial wall intima that did not overlap a sidebranch with evidence of blood flow behind the strut. ${ }^{17}$

\section{Study endpoints and definitions}

Adverse events were assessed during the hospital period as well as at one, six, and nine months, and annually as part of the protocol of the original study up to four years. The primary endpoint of the present study was the amount of neointimal hyperplasia as assessed by IVUS at eight months of follow-up. Secondary endpoints included ischaemia-driven revascularisation of the target lesion (TLR), and major adverse cardiac events (MACE). TLR was considered to be driven by ischaemia if the stenosis of the target lesion was $>50 \%$ on the basis of quantitative coronary angiography in the presence of ischaemic signs or symptoms, or if there was a stenosis of $>70 \%$ in the absence of ischaemic signs or symptoms. Revascularisation of lesions with a stenosis $<50 \%$ as assessed by QCA were not considered driven by ischaemia and were excluded from the analysis. Conversely, positive results of any non-invasive test including bicycle or treadmill exercise, single photon emission tomography imaging, and stress echocardiography sufficed to qualify as a sign of ischaemia. Of note, there was no pre-specified invasive or non-invasive test in the study protocol to evaluate the signs and symptoms of ischaemia, and none of the patients were evaluated by fractional flow reserve. TLR was defined as a repeated revascularisation based on a stenosis within the stent or within the 5-mm border proximal or distal to the stent. MACE was defined as the composite of cardiac death, myocardial infarction, or ischaemia-driven TLR. Death was classified as either cardiac or non-cardiac. ${ }^{18}$ The diagnosis of myocardial infarction after the intervention was established whenever new Q-waves of at least 0.4 seconds duration in at least two contiguous leads appeared on the electrocardiogram with an elevated creatine kinase MB fraction level, or in the absence of pathologic Q-waves, an elevation in creatine kinase levels to more than twice the upper limit of normal with an elevated creatine kinase MB or troponin I level. All adverse events and clinical endpoints were adjudicated by an independent clinical events committee.

\section{Statistical analysis}

Continuous variables are expressed as mean $\pm S D$ and categorical variables as counts and percentages. We compared continuous variables using Student's $t$ test if they were approximately normally distributed (visual inspection) or Mann Whitney test otherwise. Categorical variables were compared using Fisher's exact test or chi-square test, as appropriate. Least-squares linear regression was used to assess the association between neointimal hyperplasia and balloon-to-artery ratio at eight months. To compare clinical outcomes at eight months and four years between the groups we used relative risks. Analyses were performed in SPSS software 15.0.1. P-values are two-sided with a significance level of 0.05 . No adjustment for multiple testing was made.

\section{Results}

The first 236 patients enrolled into the SIRTAX trial were assigned to undergo IVUS examination at the time of angiographic follow-up eight months after DES implantation. After exclusion of 40 patients due to failed acquisition, inadequate pullback or poor image quality, volumetric analysis was possible in 196 patients (SES: 92; PES: 104) with 223 segments (SES: 104; PES: 119) (Figure 1) constituting the study population of the present report. Reference vessel size amounted to $2.9 \pm 0.4 \mathrm{~mm}$ with the corresponding frequency distribution shown in Figure 2. The maximal balloon pressure was $14 \pm 3 \mathrm{~atm}$ resulting in a mean BAR of $1.13 \pm 0.19$ with the frequency distribution of BAR shown in Figure 3. Based on a BAR cut-off value of 1.1, the study population was divided into a high BAR group with BAR exceeding 1.1 (110 patients, 120 segments) and a low BAR group with $\mathrm{BAR} \leq 1.1$ (86 patients, 103 segments).

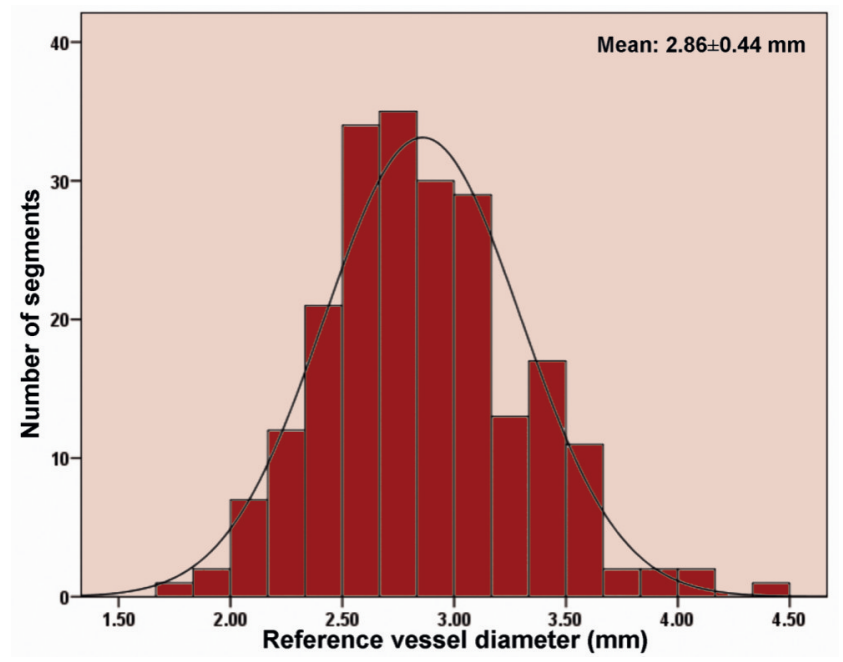

Figure 2. Histogram of pre procedure reference vessel diameter in study segments. 


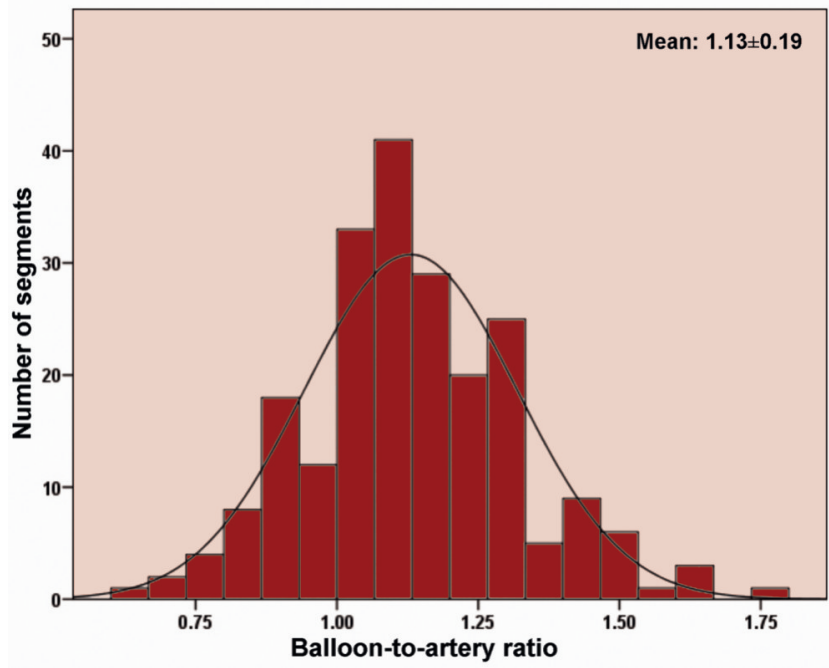

Figure 3. Histogram of balloon-to-artery ratio in study segments.

\section{Baseline clinical, angiographic and procedural data}

Baseline clinical characteristics were similar for patients in the high and low BAR groups (Table 1 ). The mean age was $60 \pm 10$ years, and $81 \%$ of patients (159 patients) were male. Pre-procedural angiographic characteristics revealed similar lesion ACC-AHA class, lesion length, percent diameter stenosis and minimal lumen diameter for both groups (Table 2). Vessel size was significantly smaller in the high BAR (RVD: $2.6 \pm 0.3 \mathrm{~mm}$ ) compared with the low BAR (RVD: $3.1 \pm 0.4 \mathrm{~mm})(p<0.0001)$ group. Conversely, stent diameter (high BAR, $3.1 \pm 0.3 \mathrm{~mm}$; low $B A R, 2.8 \pm 0.3 \mathrm{~mm}$, $\mathrm{p}<0.0001$ ), and maximal balloon pressure (high BAR, 14.8 $\pm 2.7 \mathrm{~atm}$; low BAR, $13.4 \pm 2.4 \mathrm{~atm}, \mathrm{p}<0.0001$ ) and diameter (high BAR, 3.3 $\pm 0.4 \mathrm{~mm}$; low $B A R, 3.0 \pm 0.4 \mathrm{~mm}, \mathrm{p}<0.0001$ ) were larger in the high BAR than low BAR group.

Table 1. Baseline clinical characteristics.

\begin{tabular}{lccc} 
& BAR $\leq 1.1$ & BAR>1.1 & P value \\
\hline Number of patients & 86 & 110 & \\
Age, mean \pm SD, y & $60 \pm 10$ & $60 \pm 11$ & 0.66 \\
Male, n (\%) & $71(83)$ & $88(80)$ & 0.62 \\
Hypertension, n (\%) & $45(52)$ & $63(57)$ & 0.48 \\
Current smoking, n (\%) & $40(47)$ & $42(38)$ & 0.24 \\
Diabetes mellitus, n (\%) & $15(17)$ & $18(16)$ & 0.86 \\
Dyslipidaemia, n (\%) & $48(56)$ & $74(67)$ & 0.10 \\
Family history of CAD, n (\%) & $33(38)$ & $46(42)$ & 0.61 \\
Stable angina pectoris, n (\%) & $43(50)$ & $61(56)$ & 0.44 \\
Acute coronary syndromes, n (\%) & $43(50)$ & $49(45)$ & 0.44 \\
$\quad$ Unstable angina, n (\%) & $3(4)$ & $4(4)$ & 0.17 \\
$\quad$ STEMI, n (\%) & $25(29)$ & $18(16)$ & 0.17 \\
$\quad$ Non-STEMI, n (\%) & $15(17)$ & $27(25)$ & 0.17 \\
Multivessel disease, n (\%) & $55(64)$ & $63(57)$ & 0.33 \\
Left ventricular ejection fraction, \% $\pm S D$ & $57 \pm 11$ & $59 \pm 10$ & 0.21 \\
\hline
\end{tabular}

CAD: coronary artery disease; STEMI: ST-segment elevation myocardial infarction
Table 2. Baseline angiographic and procedural characteristics.

\begin{tabular}{|c|c|c|c|}
\hline & $B A R \leq 1.1$ & BAR>1.1 & $P$ value \\
\hline Number of segments & 103 & 120 & \\
\hline LAD, n (\%) & $44(43)$ & $55(46)$ & 0.57 \\
\hline RCA, n (\%) & $35(34)$ & $43(36)$ & 0.57 \\
\hline $\mathrm{LC} x, \mathrm{n}(\%)$ & $24(23)$ & $22(18)$ & 0.57 \\
\hline \multicolumn{4}{|l|}{ ACC-AHA lesion class, $\mathrm{n}(\%)$} \\
\hline$A$ & $31(30)$ & $30(25)$ & 0.82 \\
\hline B1 & $39(38)$ & $50(42)$ & 0.82 \\
\hline B2 & $21(20)$ & $28(23)$ & 0.82 \\
\hline C & $12(12)$ & $12(10)$ & 0.82 \\
\hline Pre PCI lesion length, $\mathrm{mm} \pm \mathrm{SD}$ & $13.4 \pm 8.2$ & $13.8 \pm 7.4$ & 0.72 \\
\hline Pre PCI RVD, $m_{ \pm} \leq \mathrm{SD}$ & $3.12 \pm 0.41$ & $2.63 \pm 0.33$ & $<0.001$ \\
\hline Pre PCI MLD, mm $\pm S D$ & $0.48 \pm 0.45$ & $0.44 \pm 0.39$ & 0.52 \\
\hline $\begin{array}{l}\text { Pre PCI stenosis, } \\
\text { (\% lumen diameter } \pm \text { SD) }\end{array}$ & $84.5 \pm 13.7$ & $83.6 \pm 13.7$ & 0.65 \\
\hline SES, n (\%) & $54(53)$ & $50(42)$ & 0.12 \\
\hline PES, n (\%) & $49(48)$ & $70(58)$ & 0.12 \\
\hline Stent per lesion, n (\%) & $1.1 \pm 0.4$ & $1.1 \pm 0.4$ & 0.95 \\
\hline Stent diameter, $\mathrm{mm} \pm \mathrm{SD}$ & $2.8 \pm 0.3$ & $3.1 \pm 0.3$ & $<0.001$ \\
\hline Stent length, $\mathrm{mm}_{ \pm} \mathrm{SD}$ & $17.6 \pm 8.5$ & $19.7 \pm 10.1$ & 0.09 \\
\hline Post dilatation, $\mathrm{n}(\%)$ & $13(13)$ & $24(20)$ & 0.12 \\
\hline Maximal balloon pressure, $\mathrm{atm}_{ \pm} \mathrm{SD}$ & $13.4 \pm 2.4$ & $14.8 \pm 2.7$ & $<0.001$ \\
\hline Maximal balloon diameter, $\mathrm{mm}_{ \pm} \mathrm{SD}$ & $3.0 \pm 0.4$ & $3.3 \pm 0.4$ & $<0.001$ \\
\hline Balloon to artery ratio, mean $\pm S D$ & $0.98 \pm 0.10$ & $1.26 \pm 0.14$ & $<0.001$ \\
\hline
\end{tabular}

LAD: left anterior descending coronary artery; LCx: left circumflex coronary artery; MLD: minimal lumen diameter; ACC: American College of Cardiology; AHA: American Heart Association; PCI: percutaneous coronary intervention; RCA: right coronary artery; RVD: reference vessel diameter

\section{IVUS measurements at eight months}

IVUS volumetric data at eight months are summarised in Table 3. Stent CSA, and in-stent EEM and lumen CSA were significantly larger in the high compared with the low BAR group. Neointimal hyperplasia CSA (high BAR, $0.21 \pm 0.36 \mathrm{~mm}^{2}$; low BAR, $0.16 \pm 0.48 \mathrm{~mm}^{2}, \mathrm{p}=0.42$ ) and neointimal hyperplasia CSA percent obstruction (high BAR, 2.8 $\pm 4.5 \%$; low BAR, 2.2 $\pm 4.7 \%, p=0.32$ ) were similar in both groups. Figure 4 shows the relationship

Table 3. IVUS measurements at eight months in all segments.

\begin{tabular}{lccc} 
& BAR $\leq 1.1$ & BAR $>1.1$ & P value \\
\hline Number of segments & 103 & 120 & \\
In-stent EEM CSA, mm ${ }^{2} \pm$ SD & $14.8 \pm 4.0$ & $17.1 \pm 4.9$ & $<0.001$ \\
Stent CSA, mm ${ }^{2} \pm$ SD & $6.4 \pm 1.8$ & $7.3 \pm 2.0$ & 0.001 \\
Minimal stent CSA, mm ${ }^{2} \pm$ SD & $5.7 \pm 1.7$ & $6.5 \pm 1.9$ & 0.002 \\
Minimal stent CSA $<5 \mathrm{~mm}^{2}, \mathrm{n}(\%)$ & $35(34)$ & $19(16)$ & 0.005 \\
In-stent lumen CSA, $\mathrm{mm}^{2} \pm$ SD & $6.3 \pm 1.7$ & $7.1 \pm 1.9$ & 0.001 \\
Incomplete stent apposition, $\mathrm{n}(\%)$ & $19(18)$ & $20(17)$ & 0.74 \\
NIH CSA, mm ${ }^{2} \pm S D$ & $0.16 \pm 0.48$ & $0.21 \pm 0.36$ & 0.42 \\
NIH CSA obstruction, $\% \pm S D$ & $2.2 \pm 4.7$ & $2.8 \pm 4.5$ & 0.32 \\
\hline
\end{tabular}

CSA: cross sectional area; EEM: external elastic membrane; NIH: neointimal hyperplasia 
between neointimal hyperplasia CSA percent obstruction and BAR in all segments, revealing no correlation between the two variables $\left(R^{2}=0.003, p\right.$-value $\left.=0.40\right)$. Similarly, the relationship between neointimal hyperplasia CSA percent obstruction and BAR stratified according to stent type (SES, PES) revealed no significant correlation (SES: $R^{2}=0.013$, $p$-value $=0.25$; PES: $R^{2}=0.0003, p$ value $=0.84$ ) (Figure 5). IVUS data were analysed separately in 93 segments with small vessels (pre-procedure RVD $\leq 2.75 \mathrm{~mm}$ ) and

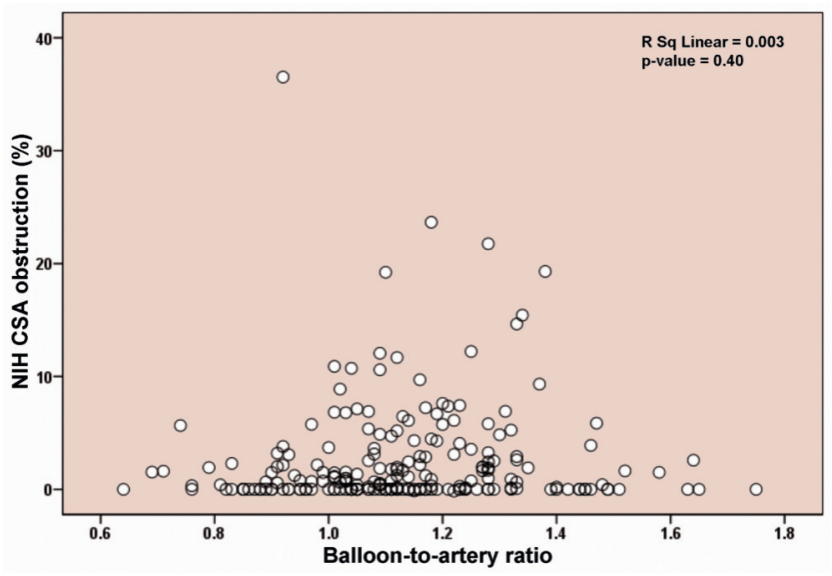

Figure 4. Relationship of neointimal hyperplasia and balloon-to-artery ratio at eight months.

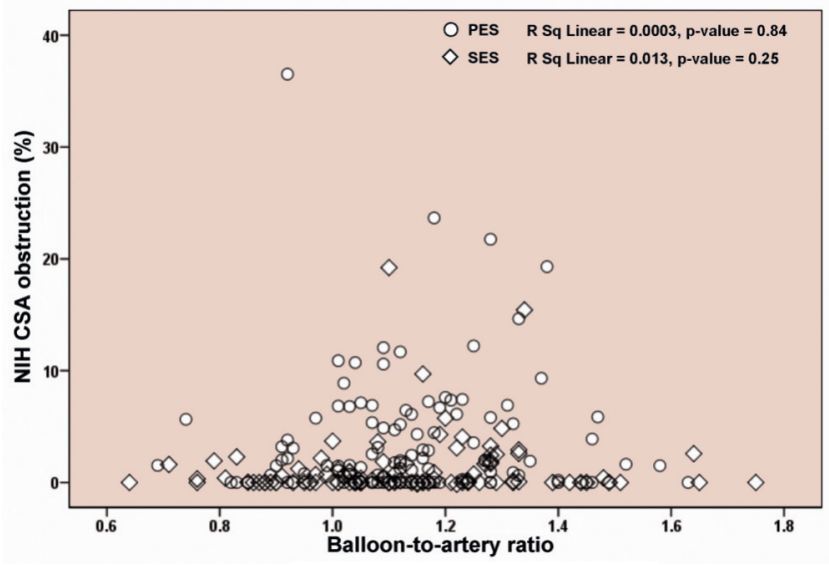

Figure 5. Relationship of neointimal hyperplasia and balloon-to-artery ratio at eight months stratified for SES and PES.
32 segments of diabetic patients. No correlation between neointimal hyperplasia CSA percent obstruction and BAR was observed in either subgroup (small vessels: $R^{2}=0.002, p$ value $=0.66$; diabetic: $R^{2}=0.118$, $p$-value $=0.054$ ) (Table 4). The 8 month angiographic late luminal loss also showed comparable numbers in the low BAR and high BAR groups, respectively (in stent: $0.15 \pm 0.40 \mathrm{~mm}$ vs. $0.15 \pm 0.36 \mathrm{~mm}, p=0.98$; in segment: $0.22 \pm 0.44 \mathrm{~mm}$ vs. $0.17 \pm 0.37 \mathrm{~mm}, \mathrm{p}=0.39$ ). Finally, rates of $\mathrm{TLR}$ and MACE were similar at eight months and four years of follow-up for both groups (Table 5).

Table 5. Clinical events at eight months and four years.

\begin{tabular}{lcccc} 
& BAR $\leq 1.1$ & BAR>1.1 & $\begin{array}{c}\text { Risk ratio } \\
(95 \% \text { CI })\end{array}$ & P value* \\
\hline Number of patients & 86 & 110 & & \\
8-month TLR, n (\%) & $2(2 \%)$ & $5(5 \%)$ & $1.95(0.39-9.83)$ & 0.41 \\
8-month MACE, n (\%) & $3(4 \%)$ & $5(5 \%)$ & $1.30(0.32-5.30)$ & 0.71 \\
4-year TLR, n (\%) & $8(9 \%)$ & $11(10 \%)$ & $1.08(0.45-2.56)$ & 0.87 \\
4-year MACE, n (\%) & $11(13 \%)$ & $13(12 \%)$ & $0.92(0.44-1.96)$ & 0.84 \\
\hline
\end{tabular}

MACE: major adverse cardiac events; TLR: target lesion revascularisation

\section{Discussion}

Neointimal hyperplasia is the result of migration of smooth muscle cells to the site of injury and extracellular matrix synthesis. While BMS effectively prevent constrictive arterial remodelling, they do not decrease but may even increase neointimal hyperplasia compared with balloon angioplasty. ${ }^{19-21}$ Neointimal hyperplasia following implantation of BMS has been shown to be proportional to the amount of arterial wall injury induced by stent struts. The latter phenomenon has been related to a more pronounced inflammatory response in relation to arterial injury..$^{2-4,6}$

In clinical practice, arterial overstretch may be encountered during implantation of stents for the following reasons:

1) The visual rather than quantitative angiographic or IVUS assessment of vessel size may lead to the utilisation of oversized balloons and stents, resulting in a mismatch between final maximal stent diameter and arterial dimensions.

2) High pressure stent implantation and post-dilatation is frequently performed in order to eliminate stent under-expansion, incomplete stent apposition, and maximise acute stent dimensions.

Table 4. IVUS measurements at eight months stratified for small vessel and diabetic subgroups.

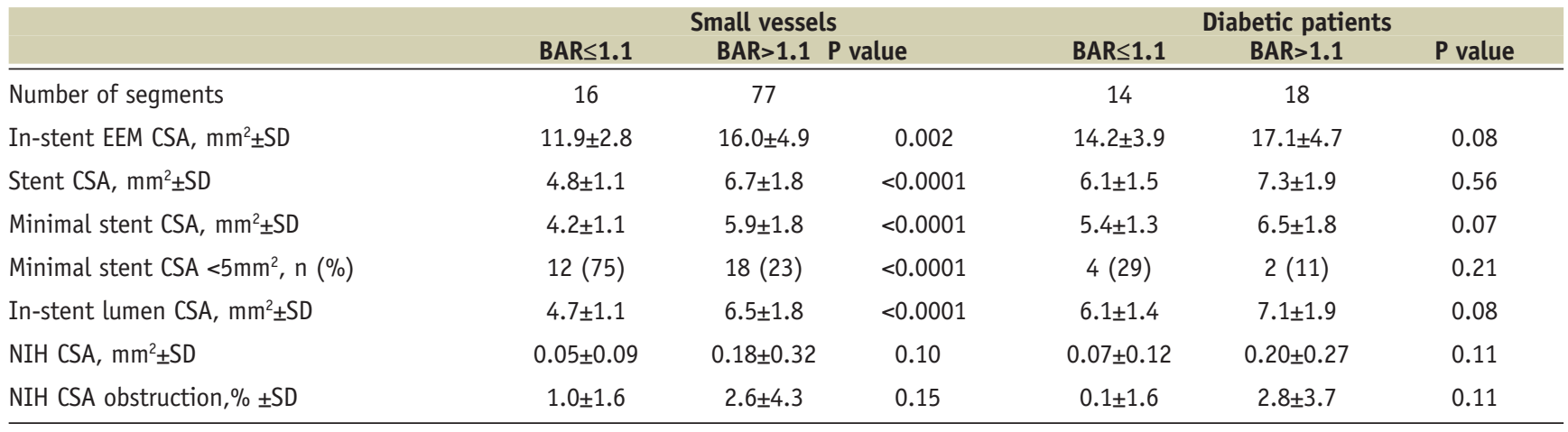

CSA: cross sectional area; EEM: external elastic membrane; NIH: neointimal hyperplasia 
Stent under-expansion and final acute stent dimensions have been identified as principal determinants of DES restenosis as well as independent predictors of early stent thrombosis. ${ }^{9-13,22-25}$ Incomplete stent apposition was also found to be more common in patients with stent thrombosis. ${ }^{9,26}$ IVUS assessment of DES implanted at conventionally used inflation pressures according to manufacturers' compliance chart revealed significant underexpansion. ${ }^{27,28}$ These observations highlight the importance of careful attention to optimal stent implantation technique ensuring adequate stent expansion in order to avoid both restenosis and stent thrombosis.

\section{Animal and human studies in the bare metal stent era}

Experimental studies have shown a direct correlation between the degree of arterial injury induced by overstretch and the amount of neointimal hyperplasia following implantation of BMS in coronary arteries. ${ }^{2-4,6}$ This phenomenon has been related to a more pronounced inflammatory reaction in response to arterial overstretch. ${ }^{6}$ Different levels of BAR $(\geq 1.1)$ have been used in numerous animal studies to induce arterial wall overstretch and the consequent vascular injury. ${ }^{2,3,6,29,30}$ Gunn et al ${ }^{2}$ investigated the impact of moderate overstretch (defined as BAR 1.25) compared with deep arterial injury. Although deep arterial injury was found to be the strongest determinator of neointimal hyperplasia, greater degrees of arterial overstretch even in the absence of deep arterial injury directly correlated with the amount of neointimal hyperplasia. While the above mentioned studies investigated the impact of a single, discrete value of arterial overstretch, Russo et al $^{3}$ assessed the effect of multiple, increasing values of BAR on neointimal hyperplasia. A total of 60 vessels in 33 swine were randomly allocated to one of five discrete BAR values ranging between 1.0 and 1.4. The results indicated a strong association between increasing BAR value and the amount of neointimal hyperplasia.

Experimental studies are limited to non-atherosclerotic coronary arteries with a follow-up duration of only 28 days. Accordingly, their results may not apply to human atherosclerotic vessels with more complex lesion characteristics such as calcified and eccentric properties. Using IVUS, Hoffmann et $\mathrm{al}^{1}$ evaluated the impact of varying degrees of BAR as well as deployment pressures on the amount of neointimal hyperplasia at a mean follow-up of 5.6 months following BMS implantation. The investigators showed a significant correlation between the degree of neointimal hyperplasia assessed by IVUS and the product of BAR and maximum inflation pressure, suggesting that BMS restenosis is related to the degree of arterial overstretch. These results were corroborated in another study, which examined the impact of vessel wall injury using serial IVUS imaging in 28 patients. ${ }^{5}$ Vessel overstretch, defined as the change in total vessel area assessed by IVUS before and immediately after stent implantation, was predictive of the amount of neointimal growth, suggesting that the latter is directly proportional to the degree of sectional vascular stretch. Kuriyama et al $^{31}$ reported the results of an IVUS study assessing overstretch in large vessels with RVD $\geq 3.0 \mathrm{~mm}$. Although neointimal hyperplasia as determined by IVUS was more pronounced in segments with than without overstretch, the increase in lumen gained by overstretch resulted in a larger final lumen as well as less percent area stenosis, suggesting that the risk of restenosis may be reduced by stent over dilatation in larger vessels.

\section{Clinical relevance of IVUS findings}

The present study is the first investigation of the impact of stretchinduced arterial injury on clinical outcome using IVUS in the DES era. Measures of clinical efficacy including TLR and MACE were similar among patients with and without increased BAR. Moreover, the degree of neointimal hyperplasia as assessed by IVUS showed no correlation with the amount of BAR. Vessel size as determined by the pre-procedural RVD was smaller in patients of the high BAR group, but did not translate into higher restenosis despite the implantation of stents with larger diameter. In addition, the results held true in two important subsets of patients deemed at increased risk of restenosis: 1) patients with small vessel disease and 2) diabetic patients.

These observations suggest that suppression of neointimal hyperplasia by DES supersedes the effect of arterial injury and that the latter does no longer constitute a significant risk factor of restenosis. The degree of arterial injury did not correlate with the amount of neointimal proliferation following implantation of DES, which is likely related to the release of antiproliferative agents strongly inhibiting the vasculoproliferative response to injury. However, stent overstretch was associated with larger lumen CSA despite a smaller pre-procedure RVD (Figure 6). Therefore, conventionally aggressive DES implantation techniques such as stent over sizing, high pressure stent implantation, or post dilatation do not appear to adversely affect long-term outcome with respect to neointimal hyperplasia and repeat revascularisation. Since adequate stent expansion has a favourable effect on clinical efficacy and may reduce the incidence of early stent thrombosis, these observations may have important clinical implications.

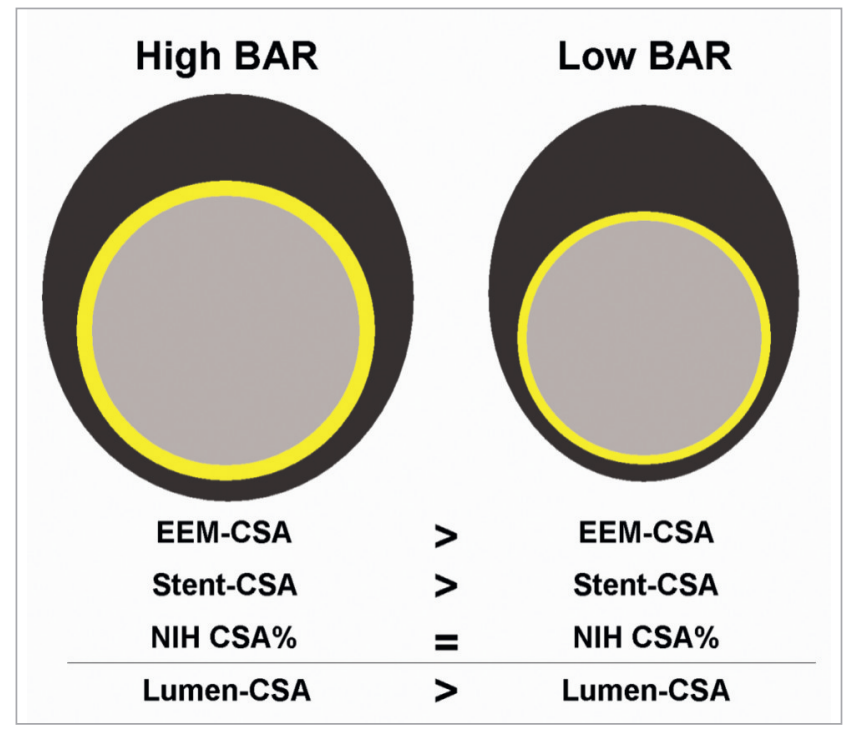

Figure 6. Schematic comparison of arterial cross sectional view at eight months follow-up in two study groups. 
In order to assess the generalisability of our results, we compared the amount of BAR in the present study with previously published trials of first generation DES. The findings are summarised in Table 6 and reveal a similar amount of BAR across a variety of studies indicating that the results may apply to a wide spectrum of patients.

Table 6. Reference vessel diameter, maximal balloon pressure, and balloon-to-artery ratio in published drug-eluting stent trials.

\begin{tabular}{|c|c|c|c|c|}
\hline Trial & Stent & RVD & $\begin{array}{l}\text { Maximal balloon } \\
\text { pressure (atm) }\end{array}$ & BAR \\
\hline SIRTAX-IVUS sub-study & SES & 2.81 & 14.3 & 1.12 \\
\hline SIRTAX-IVUS sub-study & PES & 2.88 & 13.8 & 1.13 \\
\hline ISAR-DESIRE 33 & SES & 2.60 & 14.0 & 1.18 \\
\hline ISAR-DESIRE & PES & 2.60 & 14.0 & 1.17 \\
\hline ISAR-DIABETES ${ }^{34}$ & SES & 2.70 & 13.7 & 1.15 \\
\hline ISAR-DIABETES & PES & 2.75 & 14.3 & 1.15 \\
\hline ISAR-SMART $3^{35}$ & SES & 2.44 & 13.9 & 1.19 \\
\hline ISAR-SMART 3 & PES & 2.40 & 14.3 & 1.19 \\
\hline REALITY36 & SES & 2.40 & 14.6 & NR \\
\hline REALITY & PES & 2.40 & 14.2 & NR \\
\hline LONG DES II ${ }^{37}$ & SES & 2.84 & 15.9 & 1.22 \\
\hline LONG DES II & PES & 2.82 & 14.9 & 1.24 \\
\hline PROSIT $^{38}$ & SES & 2.93 & 16.2 & 1.11 \\
\hline PROSIT & PES & 2.95 & 15.7 & 1.12 \\
\hline
\end{tabular}

BAR: balloon-to-artery ratio; NR: not reported; PES: paclitaxel-eluting stent; RVD: reference vessel diameter; SES: sirolimus-eluting stent

\section{Study limitations}

Several limitations require consideration when interpreting the results of the present study. An important limitation is the lack of a reference IVUS examination at the end of the index procedure. Therefore, there were no data regarding baseline lesion IVUS characteristics, acute and chronic stent recoil, and vascular morphology and remodelling following arterial overstretch. Moreover, BAR is a derived variable as provided by the maximal balloon dimensions in the manufacturer's compliance chart, which may differ from actually achieved BAR. In addition, the present study was an analysis of data acquired within the cohort of patients undergoing IVUS at the time of angiographic follow-up included into the SIRTAX trial without predefined randomisation to different BAR values. Histopathology represents the gold standard in the assessment of arterial injury. BAR was used as a marker of arterial overstretch in vivo, but lacks the discriminatory detail of pathological examinations, which remain restricted to ex vivo assessments. Although DES have been shown to reduce the amount of neointimal proliferation compared with BMS, the drugs and polymers attached to the surface of DES may result in vessel remodelling during longer term follow-up. Severe inflammation and hypersensitivity reactions have been reported in animal and human studies as delayed phenomena following implantation of coronary DES. ${ }^{32,39}$ The present study as an in vivo IVUS evaluation eight months after the coronary intervention using DES in humans is not able to provide histopathological data of stented arteries regarding inflammation and arterial injury during follow-up. Nevertheless, the IVUS findings at eight months as well as clinical follow-up at four years did not reveal any issues of concern.

\section{References}

1. Hoffmann R, Mintz GS, Mehran R, Kent KM, Pichard AD, Satler LF, Leon MB. Tissue proliferation within and surrounding Palmaz-Schatz stents is dependent on the aggressiveness of stent implantation technique. Am J Cardiol 1999;83:1170-4

2. Gunn J, Arnold N, Chan KH, Shepherd L, Cumberland DC, Crossman DC. Coronary artery stretch versus deep injury in the development of in-stent neointima. Heart 2002;88:401-5.

3. Russo RJ, Silva PD, Yeager M. Coronary artery overexpansion increases neointimal hyperplasia after stent placement in a porcine model. Heart 2007;93:1609-15.

4. Schwartz RS, Huber KC, Murphy JG, Edwards WD, Camrud AR, Vlietstra RE, Holmes DR. Restenosis and the proportional neointimal response to coronary artery injury: results in a porcine model. J Am Coll Cardiol 1992;19:267-74.

5. Koyama J, Owa M, Sakurai S, Shimada H, Hikita H, Higashikata T, Ikeda S. Relation between vascular morphologic changes during stent implantation and the magnitude of in-stent neointimal hyperplasia. Am J Cardiol 2000;86:753-8.

6. Kornowski R, Hong MK, Tio FO, Bramwell O, Wu H, Leon MB. Instent restenosis: contributions of inflammatory responses and arterial injury to neointimal hyperplasia. J Am Coll Cardiol 1998;31:224-30.

7. Briguori C, Tobis J, Nishida T, Vaghetti M, Albiero R, Di Mario C, Colombo A. Discrepancy between angiography and intravascular ultrasound when analysing small coronary arteries. Eur Heart J 2002;23:247-54.

8. Jensen LO, Thayssen P, Mintz GS, Egede R, Maeng M, Junker A, Galloee A, Christiansen EH, Pedersen KE, Hansen HS, Hansen KN. Comparison of intravascular ultrasound and angiographic assessment of coronary reference segment size in patients with type 2 diabetes mellitus. Am J Cardiol 2008;101:590-5.

9. Fujii K, Carlier SG, Mintz GS, Yang YM, Moussa I, Weisz G, Dangas G, Mehran R, Lansky AJ, Kreps EM, Collins M, Stone GW, Moses JW, Leon MB. Stent underexpansion and residual reference segment stenosis are related to stent thrombosis after sirolimus-eluting stent implantation: an intravascular ultrasound study. J Am Coll Cardiol 2005;45:995-8.

10. Cheneau E, Leborgne L, Mintz GS, Kotani J, Pichard AD, Satler LF, Canos D, Castagna M, Weissman NJ, Waksman R. Predictors of subacute stent thrombosis: results of a systematic intravascular ultrasound study. Circulation 2003;108:43-7.

11. Uren NG, Schwarzacher SP, Metz JA, Lee DP, Honda Y, Yeung AC, Fitzgerald PJ, Yock PG. Predictors and outcomes of stent thrombosis: an intravascular ultrasound registry. Eur Heart J 2002;23:124-32.

12. Sonoda S, Morino Y, Ako J, Terashima M, Hassan AH, Bonneau HN, Leon MB, Moses JW, Yock PG, Honda Y, Kuntz RE, Fitzgerald PJ. Impact of final stent dimensions on long-term results following sirolimus-eluting stent implantation: serial intravascular ultrasound analysis from the sirius trial. J Am Coll Cardiol 2004;43:1959-63.

13. Mintz GS. Features and parameters of drug-eluting stent deployment discoverable by intravascular ultrasound. Am J Cardiol 2007;100:26M-35M.

14. Carter AJ, Wei W, Gibson L, Collingwood R, Tio F, Dooley J, Kopia GA. Segmental vessel wall shear stress and neointimal formation after sirolimus-eluting stent implantation: physiological insights in a porcine coronary model. Cardiovasc Revasc Med 2005;6:58-64. 
15. Windecker S, Remondino A, Eberli FR, Juni $P$, Raber L, Wenaweser $P$, Togni M, Billinger M, Tuller D, Seiler C, Roffi M, Corti R, Sutsch G, Maier W, Luscher T, Hess OM, Egger M, Meier B. Sirolimus-eluting and paclitaxeleluting stents for coronary revascularization. N Engl J Med 2005;353:653-62.

16. Togni M, Windecker S, Wenaweser $\mathrm{P}$, Tueller D, Kaisaier A, Maier W, Meier B, Hess OM. Deleterious effect of coronary brachytherapy on vasomotor response to exercise. Circulation 2004;110:135-40.

17. Mintz GS, Nissen SE, Anderson WD, Bailey SR, Erbel R, Fitzgerald PJ, Pinto FJ, Rosenfield K, Siegel RJ, Tuzcu EM, Yock PG. American College of Cardiology Clinical Expert Consensus Document on Standards for Acquisition, Measurement and Reporting of Intravascular Ultrasound Studies (IVUS). A report of the American College of Cardiology Task Force on Clinical Expert Consensus Documents. J Am Coll Cardiol 2001;37:1478-92.

18. Cutlip DE, Windecker S, Mehran R, Boam A, Cohen DJ, van Es GA, Steg PG, Morel MA, Mauri L, Vranckx P, McFadden E, Lansky A, Hamon M, Krucoff MW, Serruys PW. Clinical end points in coronary stent trials: a case for standardized definitions. Circulation 2007;115:2344-51.

19. Farb A, Sangiorgi G, Carter AJ, Walley VM, Edwards WD, Schwartz RS, Virmani R. Pathology of acute and chronic coronary stenting in humans. Circulation 1999;99:44-52.

20. Weintraub WS. The pathophysiology and burden of restenosis. Am J Cardiol 2007;100:3K-9K.

21. Hoffmann R, Mintz GS, Dussaillant GR, Popma JJ, Pichard AD, Satler LF, Kent KM, Griffin J, Leon MB. Patterns and mechanisms of instent restenosis. A serial intravascular ultrasound study. Circulation 1996;94:1247-54.

22. lakovou I, Mintz GS, Dangas G, Abizaid A, Mehran R, Lansky AJ, Kobayashi Y, Hirose M, Ashby DT, Stone GW, Moses JW, Leon MB. Optimal final lumen area and predictors of target lesion revascularization after stent implantation in small coronary arteries. Am J Cardiol 2003;92:1171-6.

23. Hoffmann R, Mintz GS, Mehran R, Pichard AD, Kent KM, Satler LF, Popma JJ, Wu H, Leon MB. Intravascular ultrasound predictors of angiographic restenosis in lesions treated with Palmaz-Schatz stents. J Am Coll Cardiol 1998;31:43-9.

24. Hong MK, Mintz GS, Lee CW, Park DW, Choi BR, Park KH, Kim YH, Cheong SS, Song JK, Kim JJ, Park SW, Park SJ. Intravascular ultrasound predictors of angiographic restenosis after sirolimus-eluting stent implantation. Eur Heart J 2006;27:1305-10.

25. Takebayashi H, Kobayashi Y, Mintz GS, Carlier SG, Fujii K, Yasuda T, Moussa I, Mehran R, Dangas GD, Collins MB, Kreps E, Lansky AJ, Stone GW, Leon MB, Moses JW. Intravascular ultrasound assessment of lesions with target vessel failure after sirolimus-eluting stent implantation. Am J Cardiol 2005;95:498-502.

26. Cook S, Wenaweser $\mathrm{P}$, Togni M, Billinger M, Morger C, Seiler C, Vogel R, Hess O, Meier B, Windecker S. Incomplete stent apposition and very late stent thrombosis after drug-eluting stent implantation. Circulation 2007;115:2426-34.

27. Javaid A, Chu WW, Cheneau E, Clavijo LC, Satler LF, Kent KM, Weissman NJ, Pichard AD, Waksman R. Comparison of paclitaxel-eluting stent and sirolimus-eluting stent expansion at incremental delivery pressures. Cardiovasc Revasc Med 2006;7:208-11.

28. de Ribamar Costa J, Jr., Mintz GS, Carlier SG, Fujii K, Sano K, Kimura M, Tanaka K, Costa RA, Lui J, Na Y, Castellanos C, Biro S, Moussa I, Stone GW, Moses JW, Leon MB. Intravascular ultrasound assessment of drug-eluting stent expansion. Am Heart J 2007;153:297-303.

29. Mehran R, Mintz GS, Hong MK, Tio FO, Bramwell O, Brahimi A, Kent KM, Pichard AD, Satler LF, Popma JJ, Leon MB. Validation of the in vivo intravascular ultrasound measurement of in-stent neointimal hyperplasia volumes. J Am Coll Cardiol 1998;32:794-9.

30. Scott NA, Cipolla GD, Ross CE, Dunn B, Martin FH, Simonet L, Wilcox JN. Identification of a potential role for the adventitia in vascular lesion formation after balloon overstretch injury of porcine coronary arteries. Circulation 1996;93:2178-87.

31. Kuriyama N, Kobayashi Y, Kuroda N, Desai K, Yamamoto $Y$, Komiyama N, Komuro I, Fitzgerald PJ. Effect of coronary stent overexpansion on lumen size and intimal hyperplasia at follow-up. Am J Cardiol 2002;89:1297-9.

32. Nakazawa G, Ladich E, Finn AV, Virmani R. Pathophysiology of vascular healing and stent mediated arterial injury. Eurolntervention 2008;4 Suppl C:C7-10.

33. Kastrati A, Mehilli J, von Beckerath N, Dibra A, Hausleiter J, Pache J, Schuhlen H, Schmitt C, Dirschinger J, Schomig A. Sirolimus-eluting stent or paclitaxel-eluting stent vs balloon angioplasty for prevention of recurrences in patients with coronary in-stent restenosis: a randomized controlled trial. JAMA 2005;293:165-71.

34. Dibra A, Kastrati A, Mehilli J, Pache J, Schuhlen $\mathrm{H}$, von Beckerath $\mathrm{N}$, Ulm K, Wessely R, Dirschinger J, Schomig A. Paclitaxel-eluting or sirolimus-eluting stents to prevent restenosis in diabetic patients. N Eng/ J Med 2005;353:663-70.

35. Mehilli J, Dibra A, Kastrati A, Pache J, Dirschinger J, Schomig A. Randomized trial of paclitaxel- and sirolimus-eluting stents in small coronary vessels. Eur Heart J 2006;27:260-6.

36. Morice MC, Colombo A, Meier B, Serruys P, Tamburino C, Guagliumi G, Sousa E, Stoll HP. Sirolimus- vs paclitaxel-eluting stents in de novo coronary artery lesions: the REALITY trial: a randomized controlled trial. JAMA 2006;295:895-904.

37. Kim YH, Park SW, Lee SW, Park DW, Yun SC, Lee CW, Hong MK, Kim HS, Ko JK, Park JH, Lee JH, Choi SW, Seong IW, Cho YH, Lee NH, Kim JH, Chun KJ, Park SJ. Sirolimus-eluting stent versus paclitaxel-eluting stent for patients with long coronary artery disease. Circulation 2006;114:2148-53.

38. Lee JH, Kim HS, Lee SW, Park JH, Choi SW, Jeong JO, Cho Y, Lee N, Rhee KS, Ko JK, Seong IW. Prospective randomized comparison of sirolimus- versus paclitaxel-eluting stents for the treatment of acute STelevation myocardial infarction: pROSIT trial. Catheter Cardiovasc Interv 2008; 72:25-32.

39. Cook S, Ladich E, Nakazawa G, Eshtehardi P, Neidhart M, Vogel R, Togni M, Wenaweser P, Billinger M, Seiler C, Gay S, Meier B, Pichler WJ, Jüni $P$, Virmani R, Windecker $S$. Correlation of intravascular ultrasound findings with histopathological analysis of thrombus aspirates in patients with very late drug-eluting stent thrombosis. Circulation 2009;120:391-399. 